\title{
Teatro Avenida Hoje e sempre, fora dos eixos
}

\author{
Nuno Costa Moura
}

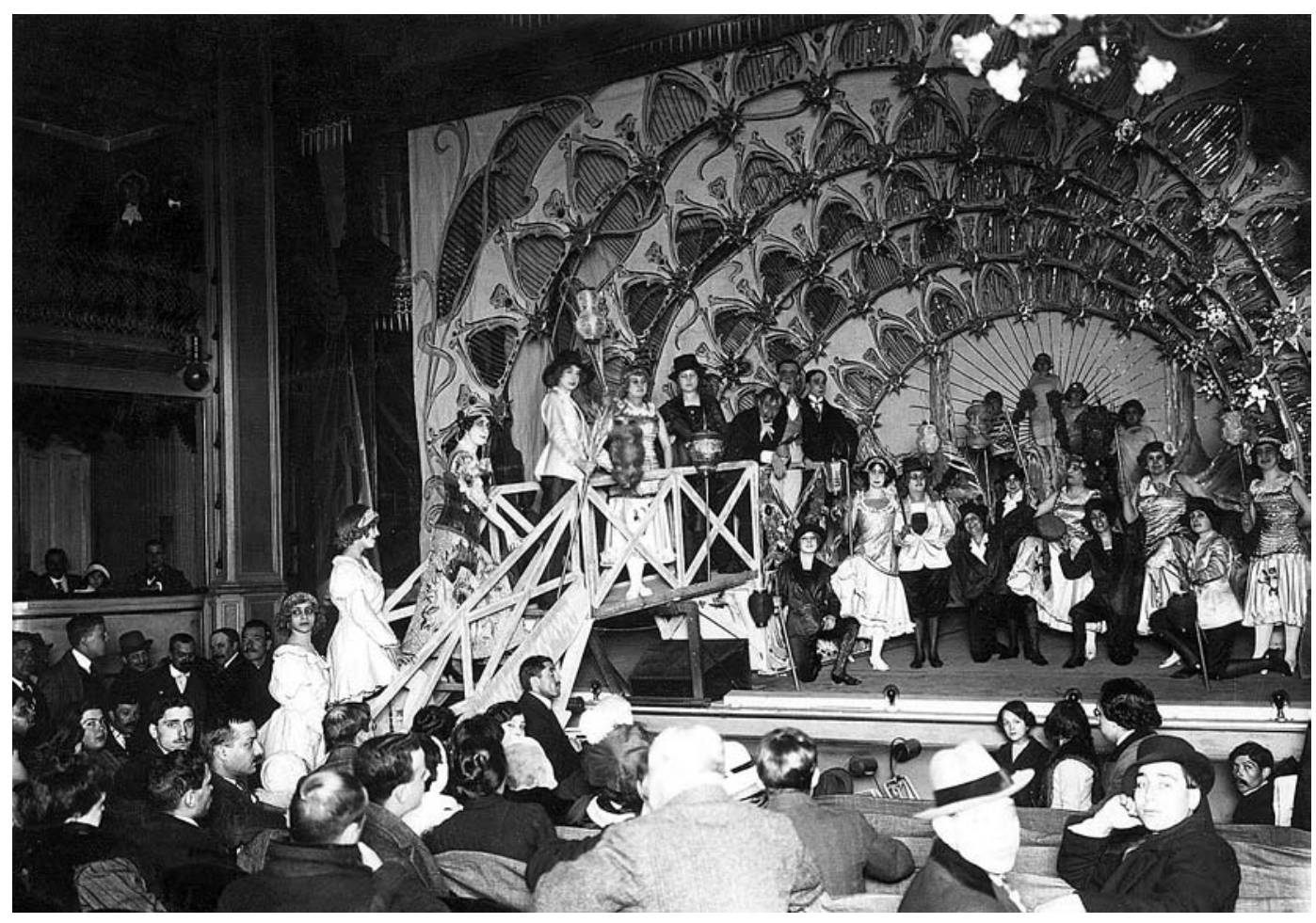

Interior do Teatro Avenida, apresentação da revista Alerta!, 1913, fot. Alberto Carlos Lima, (cortesia do Arquivo Fotográfico Municipal de Lisboa).

Quem passa por aquele edifício de escritórios da Avenida da Liberdade, nos números 150 a 156, abaixo do Teatro Tivoli, já não ouve os aplausos. Mas o cartaz desbotado que permanece à entrada do novo prédio, anunciando "hoje e sempre" a revista De fora dos eixos, não deixa esquecer. Entre 1888 e 1967 esteve ali o Teatro Avenida, palco que nunca cedeu à tentação do cinema e por onde passaram os maiores artistas teatrais portugueses: Beatriz Costa, Estêvão Amarante, Eunice Muñoz, João Villaret, Laura Alves, Maria Matos, Palmira Bastos, Ribeirinho, Vasco Santana foram apenas alguns dos actores que brilharam nas peças de teatro musicado e declamado que ai fizeram sucesso. Amélia Rey Colaço foi a sua última inquilina e, em 1965, investiu a sua fortuna pessoal para fazer reerguer um teatro moribundo. Finalmente, o Avenida parecia ter tudo para se afirmar como teatro de primeira grandeza. Mas três dias após a estreia de Felizaniversário, no fatídico 13 de Dezembro de 1967, um misterioso incêndio deitou o sonho por terra.

\section{Um lugar na cidade}

No final do século XIX, a urbanização de Lisboa para norte fez-se, essencialmente, à volta de um dos eixos de saída da capital: a Rua do Salitre. Este movimento iniciara-se, porém, muito antes com a criação do Bairro da Cotovia (actualmente da Alegria), e consolidara-se com a inauguração do Passeio Público em 1764. Dado que este parque constituía um pólo de atracção social, a urbanização mais intensa não se fez esperar. Consequentemente, surgiram outros equipamentos lúdico-culturais: o Teatro da Rua dos Condes, construído em 1765; a Praça de Touros (ou Circo) do Salitre, construída em 1780; o Teatro do Salitre, levantado ao lado do Circo em 1782 e que, em 1857, se passou a chamar Teatro de Variedades; o Circo Price, em 1860; e os Recreios Whittoyne, que abriram quando o Price fechou, em 1875.

Mas em 1886 deixava de existir o Passeio Público. À custa de expropriações e reprovação popular, Rosa Araújo rasgava Lisboa. Nascia, assim, a Avenida da Liberdade. No entanto, a nova artéria precisava de se afirmar aos lisboetas. Era no Passeio Público que Lisboa se mostrava e se via. Transformar a Avenida num novo centro passava pela construção de salas de espectáculo, até porque a construção da nova via implicara o desaparecimento de vários equipamentos de lazer (o complexo do Salitre, por exemplo). Contudo, as novas casas de espectáculos surgiram lentamente. 0 Teatro Avenida foi inaugurado em 1888; 0 
Localização futura da Avenida da Liberdade e do Teatro Avenida - 1858, Instituto Português de Cartografia e Cadastro / Eng. ${ }^{\circ}$ Filipe Folque 1856-58 (cortesia do Gabinete de Estudos

Olissiponenses).

Localização do Teatro Avenida - 1958, Instituto Geográfico e Cadastral,

1958 (cortesia do Gabinete de Estudos Olissiponenses).

'Diário ilustrado, 8 de Fevereiro de 1888, p. 1 .

2 Diário ilustrado, 9 de Fevereiro de 1888 , p. 1 .
Éden-Teatro, em 1906; o Salão Foz, em 1908. Em 1920, surgia o Parque Mayer que teve como teatros definitivos o Maria Vitória (1922), o Variedades (1926), o Capitólio (1931) e o ABC (1956). 0 cinema Tivoli (1924) e o cinema São Jorge (1950) fecharam o ciclo.

Percebe-se, então, que até 1922 o Teatro Avenida fosse o único espaço de lazer permanente a norte da Praça dos Restauradores. Sousa Bastos lamentava: "esta casa de espectáculos tem contra si o estar muito distante do centro de movimento da cidade. Na época de inverno, a mais propícia aos teatros, o espectador precisa de coragem para atravessar a Avenida, quase sempre de um desabrimento atroz, para chegar àquele teatro" (1898: 67). Todavia, anos mais tarde, João Paulo Freire contesta esta opinião, por razões compreensiveis: "Se nalgum tempo ficava fora de mão, hoje, que Lisboa alargou desconformemente os seus âmbitos, pode afoitamente dizer-se que o Teatro Avenida é um teatro central, visto que num quarteirão mais acima fica o Tivoli, que, apesar disso, se não pode considerar deslocado" (1931-39: 377).

\section{0 edifício}

0 Teatro sempre foi simples na aparência. Os elementos iconográficos que chegaram até nós (quase todos posteriores à década de 10) mostram uma fachada de dois pisos: no rés-do-chão, quatro portas de madeira; no primeiro andar, uma varanda de ferro a toda a largura da fachada; no cimo, um arco com a inscrição "Theatro da Avenida" ou "Teatro Avenida". Escreveu João Paulo Freire (idem) que o edifício "exteriormente não tem recomendação possivel" e Norberto Araújo concorda: "não possui este teatro, que alguns restauros sumários tem recebido, um maior interesse artístico" (1939: 39).

Em 1950, o proprietário do imóvel, numa exposição à Câmara Corporativa, explicava que "o Teatro Avenida foi arrendado, há cerca de 30 anos, ao empresário José Loureiro, conjuntamente com todo o mobiliário e pertences necessários ao seu funcionamento. 0 exponente deu de arrendamento, ao mesmo senhor, a cave e rés-do-chão, onde se encontram instalados os escritórios da empresa a cave e sub-cave que servem de armazém do material de cena, guarda-roupa, etc., e o terreno onde hoje está instalado o bufete do Teatro. Todos estes anexos, dependências do prédio n. ${ }^{\circ}$ 146-148 contíguo ao Teatro, ficaram em comunicação com a casa de espectáculos pela porta aberta na parede divisória dos dois prédios". A sala tinha um palco à italiana, um espaço para orquestra ao nivel da plateia, balcões, camarotes e galerias. Entre o final do séc. XIX e o ano de 1941, o número de lugares disponiveis aumentou em 96 . A tentativa de maximizar esse número foi conseguida até ao limite físico do espaço e as necessidades de exploração da actividade teatral obrigaram à invasão do edifício ao lado.

Antes da inauguração, em 1888, informava o Diário ilustrado que "os peritos que ontem passaram vistoria a este Teatro encontraram-no nas melhores condições e
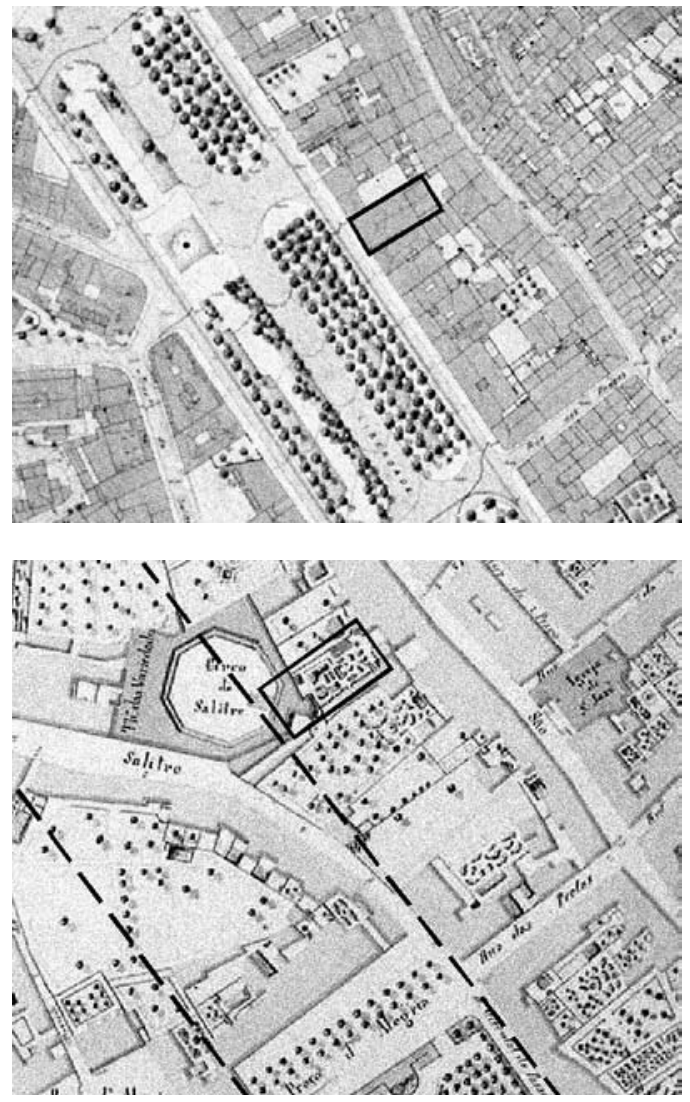

com as mais prontas e rápidas saídas. A nova e elegante casa de espectáculos é inaugurada amanhã"1,

acontecimento adiado "por não estarem ainda completos todos os trabalhos de ornamentação"2. Finalmente o Teatro abriu as suas portas ao público no dia 11 de Fevereiro e o mesmo jornal comentava: "Por um prodigio de actividade, raro em a nossa proverbial indolência, o Teatro da Avenida surgiu de um montão de escombros, no breve espaço de alguns meses, doirou-se, aformoseou-se, completou-se no rápido decurso de alguns dias, e abriu anteontem as suas portas ao público, que o contemplava, maravilhado, mal podendo crer no testemunho dos seus olhos. 0 Teatro é alegre, elegante, matizado de cores claras, brilhando à chama mordente do gaz, que o enche de luz. 0 balcão, guarnecido de cadeiras de cordovão escarlate e pregaria amarela, de um gosto original e moderníssimo, é muito bonito e desafogado, e talvez mesmo o melhor lugar do novo teatro. Os avant scènes são espaçosos e também muito elegantes, verdadeiros avant scènes parisienses. 0 pano de boca, à parte uma tal ou qual ausência de perspectiva, é de um grande efeito decorativo,

especialmente do lado direito, que apresenta um toldo oriental, realmente bem pintado. À sua entrada em cena, os dois gloriosos artistas Taborda e António Pedro foram acolhidos com ruidosas salvas de palmas e uma chuva de camélias que se alastrou no palco, transformando-o em um florente jardim"

Anos mais tarde, porém, esta visão doirada do recinto já não era partilhada por João Paulo Freire, por razões de segurança e comodidade: "O teatro é pequeno, acanhado, sem segurança para o público, em caso de incêndio, embora agora Ihe tornassem obrigatória uma saída pelo portão lateral. Entalado entre prédios, de diminutas dimensões, o corredor que serve o bufete e os urinóis, é de tal forma 


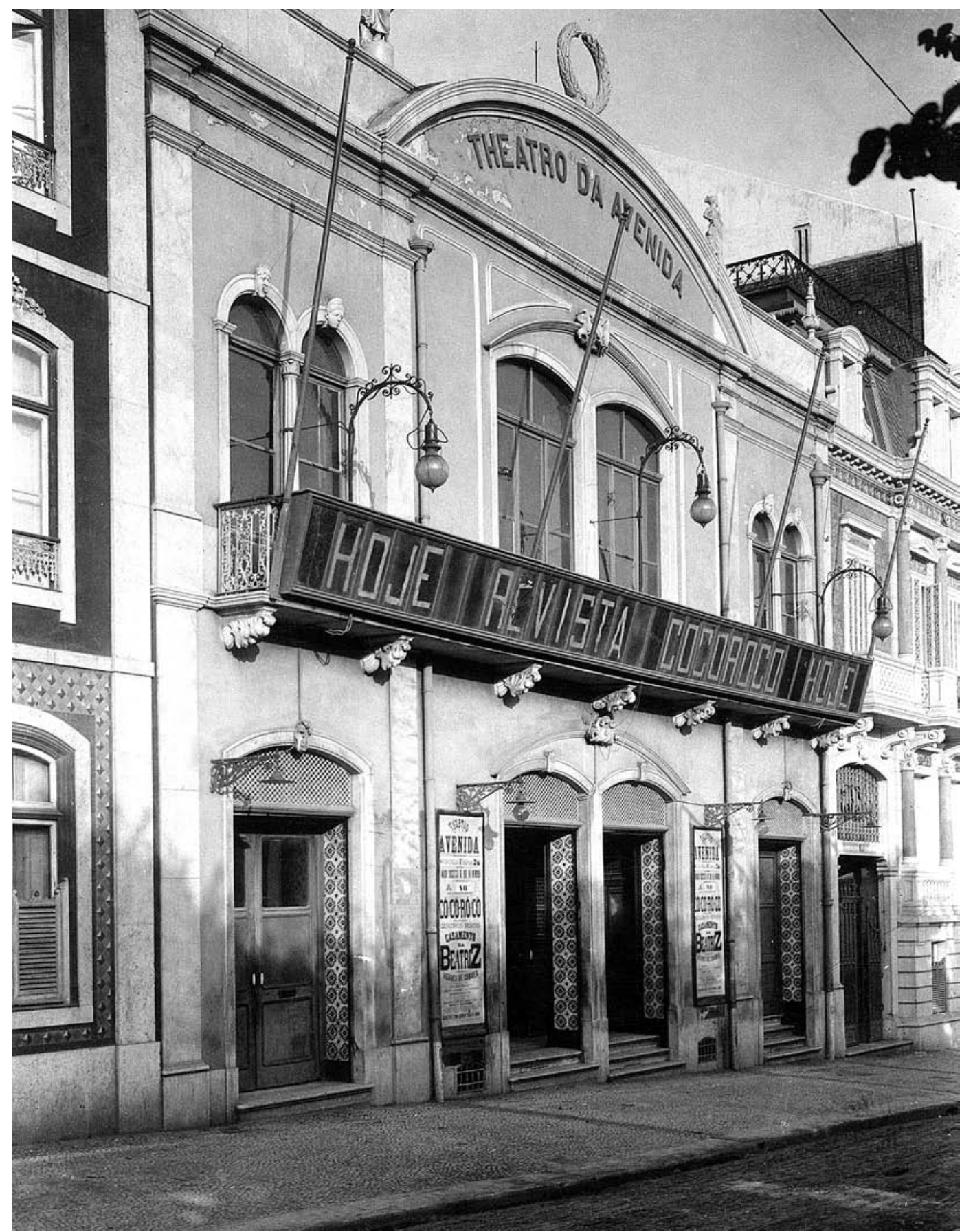

Fachada do Teatro Avenida, em cartaz a revista Có-có-ró-có, 1912, fot. Joshua Benoliel (cortesia do Arquivo Fotográfico Municipal de Lisboa).

acanhado que, em noites de enchente, quase se não dá um passo. Imaginem o que aquilo será em horas de aflição! (...) Interiormente, aparte os defeitos já apontados, é simples mas gracioso (...). 0 futuro do teatro Avenida não pode ser outro se não, ou a sua modificação radical, ou o seu desaparecimento. Tal como existe, sem suficientes garantias de comodidade e de defesa para o público, não deve ter uma longa vida, se bem que em Portugal os disparates tenham uma longevidade de múmias. (...) Não me admira, pois, primeiro, que surjam defensores do Avenida tal como ele se encontra, segundo, que a sua existência se prolongue ainda por muitos anos, entre prédios de habitação, com escadas que são autênticas ratoeiras, corredores onde se asfixia, e sem um número suficiente de saídas que sejam de segura salvação dos espectadores, em caso de sinistro" (1931-39: 377).
Num tom bem mais crítico, em 1949, António Pedro reiterava: "Ora, para começar, em Lisboa, excepção feita aos Teatros Nacionais (...), só servem como teatro as salas que, pela miséria das suas instalações, nenhum empresário quer explorar como cinema. 0 Apolo e o Avenida não são teatros, são vergonhas. Na plateia, dura e incómoda, não cabem as pernas de um espectador que passe a craveira militar. Corredores sem salas de fumo, todos os outros anexos são piores do que o mais modesto cinema de bairro. São ambos de deitar abaixo, e não se perde nada com isso, desde que antes disso se criem condições decentes para os substituir" (2001: 242).

Nos anos 60, quando a Companhia Rey Colaço / Robles Monteiro se viu obrigada a instalar-se no Avenida, depois do incêndio do Teatro Nacional D. Maria II, acrescia à penúria já notada uma visivel degradação do edifício. A 
cento e vinte e quatro

Sinais de cena 2. $2004 \quad$ Arquivo Solto

Nuno Costa Moura

Teatro Avenida: Hoje e sempre, fora dos eixos
Planta da sala do Teatro Avenida em 1922.

Planta da sala do Teatro Avenida em 1941.

${ }^{4}$ Diário popular, $14 \mathrm{de}$ Dezembro de 1967, p. 9.

${ }^{5}$ Diário de Lisboa, 14 de Dezembro de 1967, p. 16.

${ }^{6}$ Diário de Lisboa, 14 de Dezembro de 1967, p. 16.

7 Diário de Lisboa, 14 de Dezembro de 1967, p. 21.

${ }^{8}$ Diário de Lisboa, 14 de Dezembro de 1967, p. 1.

${ }^{9}$ Diário popular, 14 de Dezembro de 1967, p. 9.

${ }^{10}$ Diário de Lisboa, 14 de Dezembro de 1967, p. 17. companhia decidiu assumir a remodelação considerada essencial para a dignificação do espaço, suportando financeiramente as alterações técnicas e estéticas a cargo de Lucien Donnat. Amélia Rey Colaço investiu cerca de mil contos, " a verba recebida pelo Seguro, inferior ao valor perdido [com o incêndio do D. Maria II], que foi praticamente absorvida na remodelação da sala do Teatro Avenida que se encontrava num estado de abandono impróprio de receber uma Companhia oficial, [e] no equipamento eléctrico do palco" (Santos 1989: 262). A empresária cedeu, ainda, "mobiliário que era pertença sua: lustres (2), candeeiro de pé, tapeçarias, cortinados de veludo e jogos de maples que Amélia, devotada totalmente ao seu trabalho, levara da sua residência, ajudando com a sua iniciativa, e com os seus objectos, o engenho do decorador Lucien Donnat" ${ }^{5}$.

No dia da reabertura do Teatro Avenida, a 6 de Fevereiro de 1965, a imprensa aplaudiu. No República (7 de Fevereiro de 1965) escreveu-se que o Avenida estava "vestido de novo a esconder a sua envelhentada idade, com o mais acolhedor dos aspectos", no Diário de Lisboa (7 de Fevereiro de 1965: 5) afirmou-se que "evidentemente que ontem foi uma noite de estreia, mas é forçoso dizer-se que a grande vedeta da noite foi sem dúvida, a própria casa de espectáculos, que está transformada num pequeno teatro parisiense do melhor estilo, instalado em pleno coração de Lisboa. Por isso, para Lucien Donnatt, vai a nossa mais calorosa palavra de aplauso pelo trabalho feito".

Artur Ramos, em carta a Amélia Rey Colaço, confessouIhe: "Apresso-me portanto a vir felicitá-la pelo extraordinário dinamismo e savoir faire de que deu provas mais uma vez ao fazer reaparecer a sua Companhia dois meses depois do incêndio com um bom espectáculo numa sala surpreendentemente dignificada" (apudSantos 1989: 218).

Mas o élan não dura três anos. Às 21 horas e 20 minutos do dia 13 de Dezembro de 1967, a 25 minutos da apresentação de Feliz aniversário de Harold Pinter, ainda sem um único espectador no teatro, irrompe o fogo. Henrique Alves, fiscal do Teatro D. Maria II, lembra: "ia mandar abrir as luzes da sala quando vi, ao lado da cabina do electricista [à esquerda do palco], labaredas que vinham de baixo para cima"6. Avisou os bombeiros, que vieram logo, mas ele quase não pôde salvar nada.

As verdadeiras causas do incêndio estão ainda envoltas em mistério, embora um curto-circuito ou um calorifero não autorizado sejam as razões correntemente apontadas. Para agravar a situação, "a falta de água [ou de pressão] dificultou a acção dos bombeiros, permitindo que o incêndio se propagasse com maior velocidade"7.

0 Teatro Avenida ficara destroçado e a imprensa lamentou o acontecimento: "0 que o fogo poupou no incêndio (...) foi seriamente danificado pela água das agulhetas. Para além do proscénio, o palco e subpalco não passam de um boqueirão negro e (...) as cinzas substituíram todo o bulício do mundo fantástico que fica para além da cena". 0 Teatro Avenida estava "em escombros

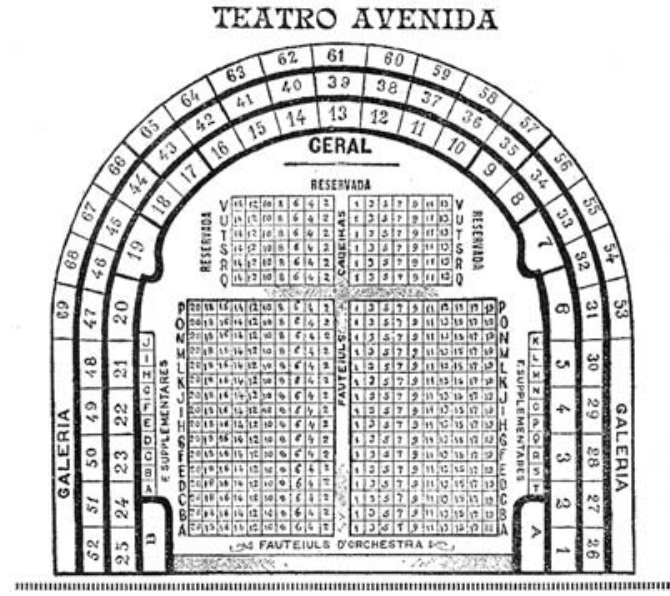

\section{- TEATRO aVENida・}

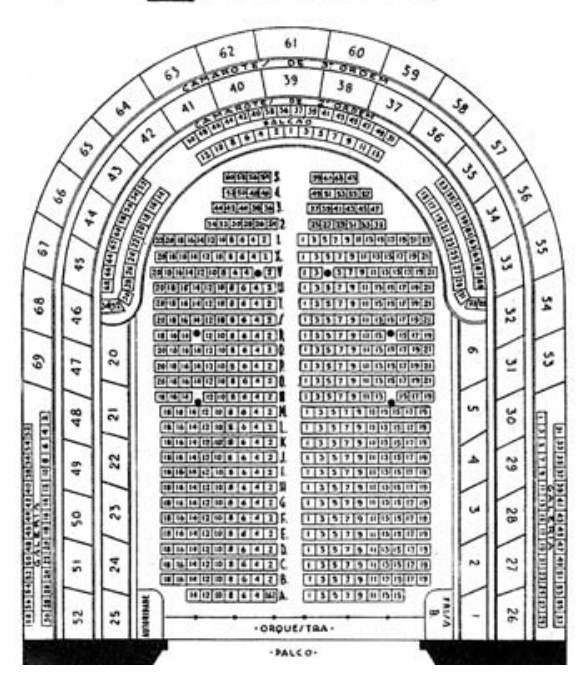

irrecuperáveis, pois só os projectores, algumas filas de plateia e pequenos lustres do corredor escaparam à sanha devoradora do incêndio. Salvaram-se apenas algumas peças que se encontravam nos camarins dos actores. As instalações do Avenida, por exíguas, não podiam albergar todo o guarda-roupa da companhia, de grande valor (...) que se encontrava guardado num armazém na Rua do Telhal. (...) 0 incêndio não atingiu as caves onde estavam instaladas as oficinas de carpintaria e os camarins dos artistas. (...) No sótão do teatro, por cima da sala, estava instalado o atelier de pintura" ${ }^{\prime \prime}$, onde se executavam os cenários das futuras peças do Capitólio, Variedades e Monumental. "A plateia está meio escondida pelo soalho da oficina de pintura que funcionava por cima da sala de espectáculos. Os varandins dourados do balcão e galerias rebentaram em diversos pontos e por toda a parte as alcatifas e passadeiras grená estão ensopadas e dificilmente recuperáveis. 0 incêndio não atingiu as alas laterais, mas a água infiltrou-se e inundou as caves e, esta manhã, cobria o pavimento da oficina de carpintaria e de alguns camarins. A empena de fundo, paralela à Rua de S. José, com o aluimento do telhado ficou meio desamparada e os Sapadores Bombeiros estão a mandar limpar o interior da sala para proceder aos trabalhos de demolição"10.

0 Avenida não voltará a reerguer-se. 0 seu destino ainda ficou pendente durante três anos até que, a 25 de Setembro de 1970, a autarquia de Lisboa decide a sua 


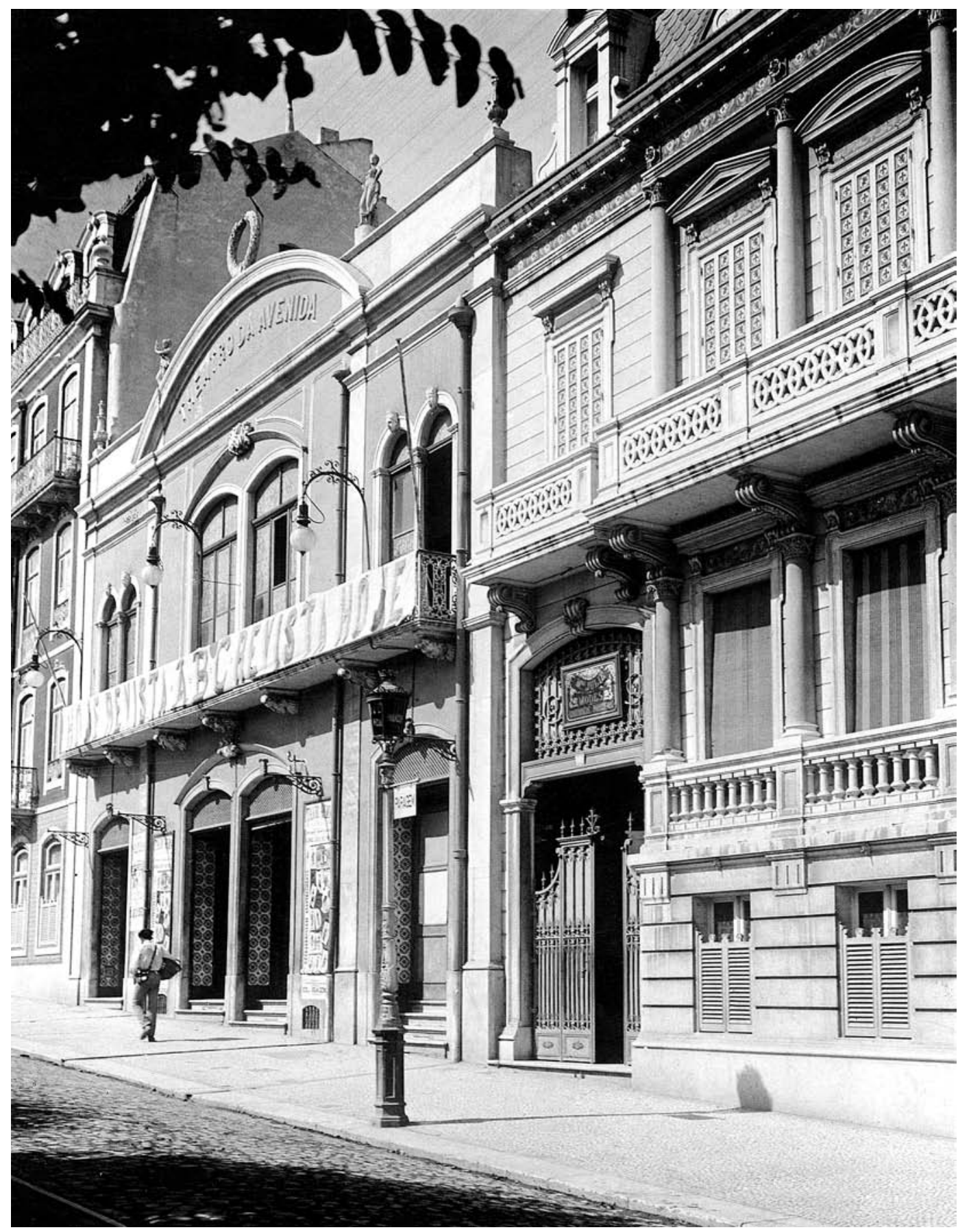

Fachada do Teatro Avenida, em cartaz a revista $A B C, 1908$, fot. Joshua Benoliel (cortesia do Arquivo Fotográfico Municipal de Lisboa).

demolição (Dias 1993: 35). No seu lugar (e no do prédio imediatamente a sul), é construído um bloco de escritórios, de nome M.C.B., que ainda existe. Nesse edificio estava prevista a construção de uma pequena sala de cinema, por imposição de lei camarária. De qualquer forma, num dos vidros desse imóvel, mantém-se o cartaz de uma das peças que passou pelo Teatro Avenida, recordando o local e perpetuando a memória de glórias passadas.

\section{Dinâmica empresarial}

A construção de casas de espectáculo em Lisboa foi particularmente activa durante a segunda metade do século XIX. 0 negócio teatral não era desprezável: havia público para os inúmeros espectáculos que se sucediam. Não admira, portanto, que, no início do ano de 1888 , se encontrasse em funcionamento um considerável número de estabelecimentos: São Carlos, D. Maria II, Trindade, Príncipe Real, Gymnasio, Chalet do Rato, Luis de Camões, Coliseo de Lisboa, Salão do Trindade, Dom Fernando II, Chalet de Variedades (em Alcântara), Chalet do Povo (em Belém), Teatro da Alegria e os Recreios Whittoyne.

Em finais dos anos 80 do século XIX, não se sabe se por nostalgia do desaparecido Circo Price ou do antigo Variedades, se por visão estratégica, João Salgado Dias decidiu construir um espaço teatral nuns terrenos que a sua mulher possuia na área. A ele juntaram-se Alexandre Mó e Silva e Ernesto Desforges que emitiram $10 \$ 000$ réis em acções e contraíram outros créditos para construir o Teatro Avenida. 0 processo foi conturbado e o desnivel do terreno fez parar a obra amiúde. 0 Teatro foi hipotecado antes de terminada a sua construção e foi vendido em hasta pública, pouco depois da inauguração. 0 Teatro 
Avenida acabou por ser adquirido pelo credor hipotecário Daniel Tavares, que passou a propriedade, anos mais tarde, para o seu filho Carlos.

Duas outras versões, sobre a iniciativa e a propriedade do Teatro e do terreno, indicam, respectivamente que: o Teatro da Avenida, "mandado construir pelo músico Miguel Ângelo Lambertini, (...) foi edificado num terreno pertencente a José Salgado Dias, que se encontrava associado a Alexandre Mó e Ernesto Desforges"'11. Ou seja, não tinha sido iniciativa de José Salgado Dias, mas sim de Miguel Ângelo Lambertini, musicólogo e construtor de pianos, grande promotor de actividades culturais na capital; Moniz Botelho, em sessão legislativa, afirmava que "existia na Avenida da Liberdade um terreno que vale agora alguns milhares de contos. Era o jardim duma propriedade que hoje me pertence e que dela foi destacado nas condições que vou expor. Apareceu uma empresa a pretender adquirir o terreno para nele construir o Teatro Avenida. 0 terreno não podia ser vendido, por constituir bem dotal de minha avó materna. Mas a empresa prontificou-se a aforá-lo por $50 \$ 000$ réis por mês, em moeda metálica de ouro ou prata, e um camarote do Teatro. Fez-se o aforamento, a senhoria directa julgou-se ao abrigo de quedas de moedapapel, construiu-se a casa de espectáculos e rodaram os tempos"12.

É geralmente aceite que a primeira empresa de exploração pertencia aos três promotores do edifício, mas cedo Ernesto Desforges se tornou o único empresário do espaço. Foi uma aventura de pouco tempo já que, em Maio do mesmo ano, era alugado a Alves Rente, que o ocupou durante uma temporada com a companhia do Principe Real, do Porto. Seguiu-se Sousa Bastos que o explorou por dois meses, durante a Exposição Industrial da Avenida. Passaram pelo Teatro Drummond, com companhias francesas, espanholas e portuguesas, Ciriaco Cardoso, Edmundo Cordeiro, Cinira Polónio, Barata, Salvador Marques, Afonso Taveira, Pepa, Sousa Bastos (outra vez), José Ricardo, José Saraga, Luís Galhardo e Armando de Vasconcelos, até depois da instauração da República. Sobre esta última gerência, disse Carlos Santos que "tendo caducado, porém, o meu contrato de aluguer naquele teatro [Inverno de 1918, no Gymnasio], logo

${ }^{11}$ República, 14 de Dezembro de 1967, p. 8

${ }^{12}$ Diário n. 035 da 1 sessão da V Legislatura, de 22 de Março de 1950

${ }^{13}$ República, 14 de Dezembro de 1967, p. 8

${ }^{14}$ Diário popular, $14 \mathrm{~d}$ Dezembro de 1967, p. 9

${ }^{15}$ Diário de Lisboa, 14 de Dezembro de 1967, p. 17 transitei com a mesma companhia [Palmira, Brazão, Stichini, entre outros] para o Avenida, ainda mais valorizada com a entrada de outros artistas e onde Armando de Vasconcelos, ao tempo detentor daquela casa de espectáculos, teve a gentileza de não só a ceder mas até associar-se comigo, entregando-me, no entanto, num gesto absolutamente espontâneo, a escolha do repertório e a sua direcção artística" (1950: 280).

Até 1910, o Teatro Avenida deu prejuizo à maioria das companhias. Os poucos sucessos foram as reposições da revista Tim tim por tim tim, de Sousa Bastos, e da opereta O burro do Sr. Alcaide, de Gervásio Lobato e D. João da Câmara. Não espanta, por isso, que em 1908 o Almanaque enciclopédico ilustrado escrevesse: "0 Teatro
Avenida na actual época explora a opereta. Pode ser que desta feita termine a "macaca" que ordinariamente o persegue" ${ }^{113}$. De facto, foi com os géneros populares que o Avenida conheceu os seus maiores êxitos de público (e, por inerência, o sucesso comercial), especialmente nas décadas de 20 e 30, com a dupla Luiza Satanela / Estevão Amarante e as companhias de Maria Matos, Palmira Bastos, Chaby Pinheiro e Alves da Cunha.

Carlos Tavares celebrou, em 1923, o último contrato de arrendamento com o empresário José Loureiro, tendo passado, por morte deste, para a viúva, Beatriz Cervantes Loureiro, que acabou por ceder o Avenida, em regime de exploração, à empresa de Vasco Morgado, no ano de 1951. Foi este que o subalugou à Companhia Rey Colaço / Robles Monteiro em 1965. Sobre este Teatro, Amélia Rey Colaço escreveu que "a diferença de prestígio do Teatro Nacional de D. Maria II, relativamente ao Teatro Avenida, reflecte-se na bilheteira e no tempo de duração das peças em cena, de forma incalculável" (apud Santos 1989: 261).

Na noite de 13 de Dezembro de 1967, o Avenida ardeu. No entanto, o destino do Teatro era discutido há já bastante tempo. Nos anos 50, "o proprietário do teatro e do prédio contíguo tornou pública a intenção de os vender, indiferente ao destino que o futuro reservasse à velha casa de espectáculos. Não faltaram, então, sugestões de intervenção do Município e da Fundação [Calouste] Gulbenkian, para que nos terrenos ocupados pelos dois prédios se construisse um grande e moderno teatro. Mas a ideia ficou por ali"14. Ao proprietário interessava mais a construção de um prédio de rendimento, pelo que "moveu uma acção de despejo, que foi julgada improcedente. [Em 1967 estava] em curso uma nova acção de despejo movida contra o arrendatário [José Loureiro, Sucessora] e aquelas duas empresas [Vasco Morgado e Rey Colaço / Robles Monteiro]. Essa acção foi também julgada improcedente, em 1a instância, encontrando-se pendente um recurso para o tribunal da Relação"15. 0 incêndio resolveu a querela e construiu-se um prédio de escritórios no seu lugar.

Em 1949, José Gamboa culpava os empresários pelo encerramento do Avenida, perante a óbvia falta de casas de espectáculos para os artistas portugueses. Irritava-se com o facto de "o Teatro Avenida se conservar encerrado na época própria ou exibir companhias estrangeiras?!" (Gamboa 1949: 161). De facto, o Avenida manteve-se durante 10 meses encerrado naquele ano - o mais longo periodo de inactividade - devido à falência do italiano Piero. Gamboa referia, ainda, os termos gravosos em que o Teatro era cedido às companhias, que tinham "que trabalhar em sessões - condição sine qua non da cedência do teatro pagar de renda $12 \%$ da receita bruta e mais $1.200 \$ 00$ de cativos... diariamente!!!" (idem). Explicava, igualmente que "o arrendatário [José Loureiro] do Teatro Avenida é o proprietário do Teatro Trindade. E este último aluga-o para cinema. (...) Aquele de que é arrendatário, como é uma velha e desconfortável barraca que não serve para cinema, também não o explora directamente, mas subarrenda-o para 

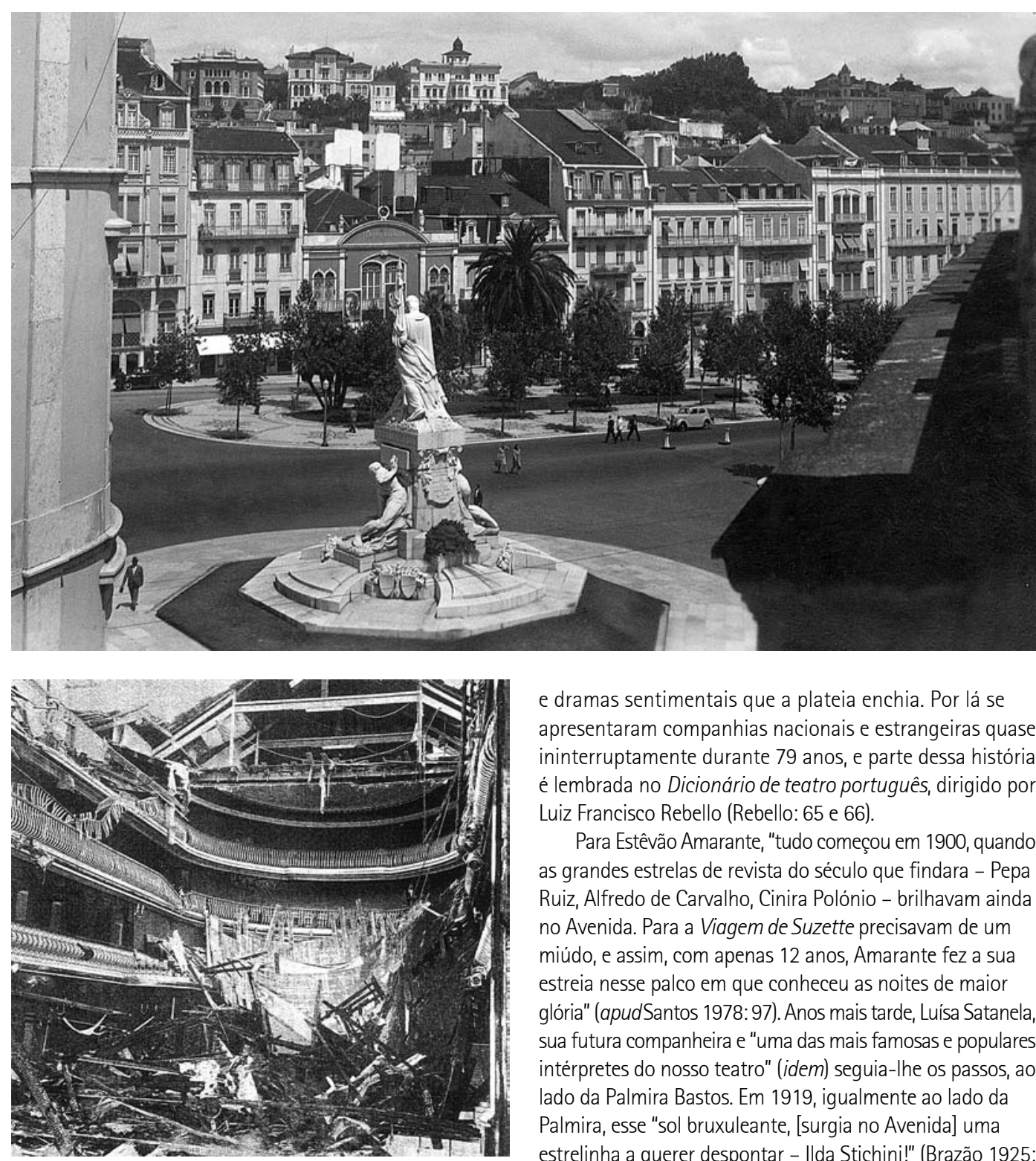

espectáculos de teatro - preferentemente de revista, sempre em sessões. (...) Este benemérito teatral, que aufere rendas fabulosas pelo aluguer dos dois teatros, paga ao senhorio daquele em que é arrendatário uma importância tão ridicula que, por vezes, recebe dos sublocatários num só mês, muito mais do que entrega ao proprietário num ano!!!... Desta forma, se encontra loucos ou aventureiros que tho tomem por sublocação, o velho e abarracado Teatro Avenida é um autêntico filão de oiro... Se está fechado, favorece a táctica cinéfila do Trindade - exactamente o que, de momento, mais Ihe convém..." (ibidem).

\section{Ocupação artística}

0 Teatro Avenida estreou-se a 11 de Fevereiro de 1888, num sábado de Carnaval, com duas peças: 0 tio Torquato, comédia em 1 acto de A. de Ataíde, com o actor Taborda a garantir o sucesso, e De Herodes a Pilatos, nova comédia em 3 actos, numa tradução de Guilherme Celestino, com António Pedro e que não agradou nem ao público nem à critica.

Pelo Teatro Avenida passaram quase todos os géneros teatrais, mas era nas operetas, revistas, farsas, comédias e dramas sentimentais que a plateia enchia. Por lá se apresentaram companhias nacionais e estrangeiras quase ininterruptamente durante 79 anos, e parte dessa história é lembrada no Dicionário de teatro português, dirigido por Luiz Francisco Rebello (Rebello: 65 e 66).

Para Estêvão Amarante, "tudo começou em 1900, quando as grandes estrelas de revista do século que findara - Pepa Ruiz, Alfredo de Carvalho, Cinira Polónio - brilhavam ainda no Avenida. Para a Viagem de Suzette precisavam de um miúdo, e assim, com apenas 12 anos, Amarante fez a sua estreia nesse palco em que conheceu as noites de maior glória" (apudSantos 1978: 97). Anos mais tarde, Luisa Satanela, sua futura companheira e "uma das mais famosas e populares intérpretes do nosso teatro" (idem) seguia-Ihe os passos, ao lado da Palmira Bastos. Em 1919, igualmente ao lado da Palmira, esse "sol bruxuleante, [surgia no Avenida] uma estrelinha a querer despontar - Ilda Stichini!" (Brazão 1925: 212). "Também Eunice [Muñoz], que nem quinze anos ainda fizera, foi chamada ao Teatro Avenida" (Santos 1991: 32).

"Aqui tive alguns dos meus maiores êxitos: Joana d'Arc, Anna Sullivan, etc.", lembra a actriz (apudSantos, ibidem). Foi nesse palco, igualmente, que se estrearam Luís de Sttau Monteiro como encenador (com O milagre de Anna Sullivan) e Vasco Morgado como actor na peça Está lá fora o inspector de Priestley.

Alguns êxitos mereceram notas efusivas de críticos e artistas de teatro. Assim, com "enchentes sucessivas [a eterna Palmira apresentou em 1921] Os conquistadores e Guardado está o bocado..." (Santos 1959: 290). Beatriz Costa confessou que teve "uma temporada feliz no Teatro Avenida, com Nascimento Fernandes [e que ai fez] duas peças: uma comédia e uma comédia dramática. A garota da sorte deu-me uma grande alegria, mas mandei o género às urtigas..." (1976: 103). Depois da prolongada estadia no Brasil, foi no Avenida que a artista tentou o seu regresso aos palcos portugueses, em 1949: "Os números eram bons e a reaparição foi um sucesso" (Santos 1978: 109). Outro "lucro de bilheteira [foi a farsa] O meu menino, onde Nascimento Fernandes e Vasco Santana [faziam] as delícias dos amadores do género" (Freire 1931-39: 377).
Avenida da Liberdade e Teatro Avenida,1931, fot. Eduardo Portugal (cortesia do Arquivo Fotográfico Municipal de Lisboa).

Interior do Teatro Avenida após o incêndio de 13 de Dezembro de 1967, in Diário de Lisboa, 14 de Dezembro de 1967, p. 1. 
0 teatro foi ainda lugar importante de trabalho para artistas de renome. A grande Maria Matos permaneceu no Avenida longas temporadas e Costa Ferreira recorda que ela, nos "10 anos seguidos no Teatro Avenida nos dava a impressão de fazer sempre a mesma peça que ela transformava todas as noites com prodígio de talento" (1985: 114). Alves Cunha, em 1955, interpretou "o personagem de juiz [na peça Alouette, de Anouilh], que seria o seu último trabalho no teatro" (Silva 1992: 65). Em 1965 é filmada, a partir do Teatro Avenida, a peça As árvores morrem de pé, de Alexandre Casona. Foi uma das primeiras peças a serem gravadas para a RTP directamente de um teatro e uma das que mais marcou a carreira de Palmira Bastos.

Assim, praticamente todos os grandes e populares actores portugueses passaram pelo Avenida: Adelina Abranches, Alves da Cunha, Amélia Rey Colaço, Ângela Pinto, António Pinheiro, António Silva, Armando Cortez, Assis Pacheco, Beatriz Costa, Brunilde Júdice, Carlos Santos, Carmen Dolores, Chaby Pinheiro, Costa Ferreira, Eduardo Brazão, Elvira Velez, Erico Braga, Ester Leão, Estêvão Amarante, Eugénio Salvador, Eunice Muñoz, Hermínia Silva, Hortense Luz, Ilda Stichini, Irene Izidro, João Villaret, Laura Alves, Lucília Simões, Luisa Satanela, Lurdes Norberto, Madalena Sotto, Maria Lalande, Maria Matos, Mercedes Blasco, Milú, Nascimento Fernandes, Palmira Bastos, Pepa Ruiz, Raul Solnado, Ribeirinho, Rogério Paulo, Samuel Dinis, Taborda, Teresa Gomes, Varela Silva e Vasco Santana, entre outros.

\section{Um lugar na memória}

0 Teatro Avenida surgiu de uma vontade de alargar o eixo Trindade / S. Carlos / D. Maria, mas a sua aceitação pública não foi imediata. Nunca chegou a partilhar o prestígio dessas casas, apesar do sucesso público das comédias, revistas, farsas e dramas sentimentais que apresentou entre os anos 10 e 30 do século XX. Esses foram os seus momentos de glória. A sua ocupação pelo Teatro Nacional, na década de 60, foi uma peripécia de percurso.

Sem uma programação uniforme, oscilava entre o declamatório D. Maria e o revisteiro Parque Mayer. Apesar disso ou por essa razão, praticamente nunca esteve fechado, mantendo uma actividade regular ao longo dos seus quase 80 anos. 0 Avenida nunca desvirtuou o seu primeiro propósito - o teatro -, sendo dos poucos a resistir ao cinema e a outros apelos comerciais.

0 Avenida era simples e modesto: um teatro com condições técnicas que rapidamente se tornaram obsoletas, apesar das intervenções regulares e do alargamento da sala e das instalações. Destruído pelo fogo, todos o lamentaram.

0 Avenida manteve sempre o nome e a identidade. Pouco apelativo às elites, sempre foi o "popular Avenida" (Ferreira 1985: 161).

\section{Referências bibliográficas}

AA. W. (1992), Arqueologia e recuperação dos espaços teatrais, Lisboa, Acarte / Fundação Calouste Gulbenkian.

ARAÚJ0, Norberto / BARATA, Martins (1939), Peregrinações em Lisboa, Lisboa, Parceria A. M. Pereira.

BASTOS, Sousa (1898), A carteira do artista: Apontamentos para a história do tea tro português e brasileiro acompanhadas de notícias sobre os principais artistas, escritores e compositores estrangeiros, Lisboa, Antiga Casa Bertrand.

- - (1908), Dicionário de teatro português, Lisboa, Imprensa Libânio da Silva (edição fac-similada, Coimbra, Minerva, 1994).

BRAZÃO, Eduardo (1925), Memórias de Eduardo Brazão (compiladas pelo seu filho e prefaciadas por Henrique Lopes de Mendonça), Lisboa, Empresa da Revista de Teatro.

COSTA, Beatriz (1976), Sem papas na lingua, Mem Martins, Europa-América. DIAS, Marina Tavares (1993), Lisboa desaparecida (vol. 2), Lisboa, Quimera. FERREIRA, Costa (1985), Uma casa com janelas para dentro (Memórias), Lisboa, INCM-SPA.

FREIRE, João Paulo [Mário] (1931), Lisboa do meu tempo e do passado: Do Rocio à Rotunda, Lisboa, Parceria António Maria Pereira.

- - (1937), Minudências lisboetas, Porto, Livraria Simões Lopes. GAMBOA, José (1949), A propósito de teatro: Algumas considerações oportunas oferecidas à inteligência e reflexão de todos os homens de boa vontade, Lisboa, Edição de autor.

PEDRO, António (2001), Escritos sobre teatro, introdução, selecção e notas de Fernando Matos Oliveira, Porto, Lisboa e Coimbra, TNSJ, Edições Cotovia, Angelus Novus.

REBELLO, Luiz Francisco (dir.) (s/d), Dicionário do teatro português, Lisboa, Prelo (incompleto: até à letra L).

SANTOS, Carlos (1950), Cinquenta anos de teatro: Memórias de um actor, Lisboa, Editorial Noticias.

SANTOS, Vitor Pavão dos (1978), A revista à portuguesa: Uma história breve do teatro de revista, Lisboa, 0 jornal.

- - (selecção e notas) (1989), A companhia Rey Colaço / Robles Monteiro, Correspondência (1921-1974), Lisboa, Museu Nacional do Teatro.

- - (org.) (1991), Eunice Muñoz: 50 anos de vida de uma actriz, Lisboa, Secretaria de Estado da Cultura, Museu Nacional do Teatro.

SILVA, Varela (1992), Camarim com janela para a rua: Histórias de teatro, Lisboa, Editorial.

Agradecimento a J.N.M. 


\section{$\mathrm{APCT}$ I, \\ Associação Portuguesa}

Presidente honorário $\quad$ Carlos Porto

\begin{tabular}{l|l} 
Direcção & $\begin{array}{l}\text { Maria Helena Serôdio } \\
\text { Paulo Eduardo Carvalho } \\
\text { Rui Cintra }\end{array}$
\end{tabular}

Assembleia Geral $\quad$ Luiz Francisco Rebello Fernando Midões

Conselho Fiscal Ana Isabel Vasconcelos Maria João Caetano Mónica Guerreiro

ESTATUTOS Capitulo Primeiro (Da Associação e dos seus fins)

Art. ${ }^{2} .^{\circ}$

A Associação tem por objectivo:

Dignificar, estruturar e responsabilizar a actividade crítica relativa à teoria e prática do teatro, entendendo-se por actividade crítica não só a crítica de espectáculos, mas também tudo aquilo que diga respeito à informação, reflexão e teorização no campo das artes performativas.

\section{Colaboração com Sinais de cena}

A revista está aberta à participação de quem deseje colaborar enviando artigos que julgue corresponderem aos objectivos da publicação e às modalidades enunciadas pelas rubricas existentes. A consulta do sítio da APCT na Internet (www.apcteatro.org) e o contacto por correio electrónico (geral@apcteatro.org ou estudos.teatro@fl.ul.pt) são indispensáveis para conhecer as normas de apresentação dos artigos (dimensão, aspecto gráfico, citações, referências bibliográficas, ilustrações, etc.).

\section{ASSINATURA}

Desejo subscrever os números 3 e 4 da revista Sinais de cena (correspondentes a Junho e Dezembro de 2005), no valor total de 22,00 a beneficiando assim de um desconto sobre o preço de venda ao público.

Fora do pais: Europa 24,00 a / Fora da Europa 26,00 a.

Nome:

Morada:

\begin{tabular}{|l|l} 
Código postal: & Pais:
\end{tabular}

Endereço electrónico:

\begin{tabular}{|l|l|l|} 
Forma de pagamento: $\square$ Vale postal $\square$ Cheque $n^{\circ}$. & Banco \\
\hline
\end{tabular}

Preencha e envie este cupão (ou fotocópia do mesmo) para: 
